\title{
O ensino de música no Maranhão: uma análise nos livros escolares de Perdigão (1869) e Rayol (1902)
}

The teaching of music in the state of Maranhão: a Perdigão (1869) and Rayol (1902) school books analysis

El ensino de música en el Maranhão: un análisis en los libros escolares de Perdigão (1869) y Rayol (1902)

\author{
Kathia Salomão \\ Escola de Música do Estado do Maranhão (Brasil) \\ Universidade Federal do Pará (Brasil) \\ https://orcid.org/0000-0001-5606-1089 \\ http://lattes.cnpq.br/4489575016531288 \\ kathiasalomao@,hotmail.com \\ César Augusto Castro \\ Universidade Federal do Maranhão (Brasil) \\ Universidade Federal do Pará (Brasil) \\ Bolsista de Produtividade em Pesquisa do CNPq \\ https://orcid.org/0000-0001-7650-895X \\ http://lattes.cnpq.br/2060977814636465 \\ ccampin@terra.com.br
}

\section{Resumo}

A pesquisa a respeito dos materiais escolares se tornou relevante no campo da história da educação no Brasil, incluindo a dos livros escolares. Sabendo-se dessa relevância, este trabalho visa analisar os livros Principios elementares de Musica (1869) e Noções de Musica (1902), dos maranhenses Domingos Perdigão e Antonio Rayol, respectivamente. Utiliza-se a pesquisa bibliográfica, priorizando autores que tratam da temática, como Bittencourt (2008) e Chopin (2002), e a pesquisa documental em documentos oficiais e jornais. A análise dessas obras levou em consideração os conteúdos selecionados, a forma de apresentação, o público e os fins a que foram destinadas. Os conteúdos abordados pelos autores correspondem aos elementos da grafia musical tradicional, apresentando ilustrações apenas no livro de Perdigão. Essas obras tiveram como público-alvo os alunos desses autores em escolas ludovicenses.

Palavras-chave: Cultura material. Livros escolares. Ensino de música. 


\begin{abstract}
The research on school material became relevant in the field of history of education in Brazil, including the one on school books. Knowing about this relevance, this work is aimed at analyzing the books Elementary principles of music (1869) and Notions of music (1902) by Domingos Perdigão and Antonio Rayol respectively, from Maranhão. Bibliographic research is used, prioritizing authors that deal with the theme, such as Bittencourt (2008) and Chopin (2002), and documentary research in official documents and newspapers. The analysis of these works took into account the contents selected, the form of presentation, the public and the purposes for which they were intended. The contents approached by the authors correspond to the elements of the traditional musical spelling, presenting illustrations only in the book of Perdigão. Such works had as target audience the students of these authors in schools of São Luís.
\end{abstract}

Keywords: Material culture. School books. Music teaching.

\title{
Resumen
}

La investigación sobre los materiales escolares se hizo relevante en el campo de la historia de la educación en Brasil, incluyendo la de los libros escolares. Sabiéndose de esa relevância, este trabajo visa analizar los libros Principios elementares de musica (1869) y Noções de musica (1902), de los maranhenses Domingos Perdigão y Antonio Rayol, respectivamente. Utilízase la investigación bibliográfica, priorizando autores que tratan de la temática, como Bittencourt (2008) y Chopin (2002), y la investigación documental en documentos oficiales y periódicos. El análisis de estas obras tuvo en cuenta los contenidos seleccionados, la forma de presentación, el público y los fines a que se destinaron. Los contenidos abordados por los autores corresponden a los elementos de la grafía musical tradicional, presentando ilustraciones apenas en el libro de Perdigão. Estas obras tuvieron como público objetivo a los alumnos de esos autores en escuelas ludovicenses.

Palabras clave: Cultura material. Libros escolares. Enseñanza de música. 


\section{Introdução}

Os materiais escolares se tornaram relevantes para as práticas educativas ao longo dos últimos séculos. Daí, pesquisas vêm sendo realizadas sobre esses materiais, dentre eles os livros didáticos ${ }^{1}$. Rocha e Somoza (2012, p. 28) acreditam que os estudos sobre a história da educação permitem pensar o manual escolar ${ }^{2}$ como um objeto cultural que possui uma variedade de "intenções, objetivos, regulações", assim como um meio de conhecimento "sobre os valores partilhados em uma determinada época; sobre as representações sociais; e sobre as práticas escolares".

Com a vinda da corte para o Brasil, em 1808, instalou-se a Impressão Régia, cuja finalidade incluía a produção de materiais para o ensino público, embora muitos desses fossem apenas traduções de livros estrangeiros. Nesse mesmo período, a produção de obras didáticas começou a se efetivar também em editoras particulares, tanto na corte quanto nas províncias, sendo estas, muitas vezes, tipografias mais especializadas em jornais (BITTENCOURT, 2008). Esse movimento, assim como a busca por materiais com uma linguagem voltada à realidade brasileira, favoreceu a produção e a publicação de livros escolares nacionais.

Nesse contexto foram produzidos os livros de Domingos Thomaz Vellez Perdigão e Antonio dos Reis Rayol, dois renomados músicos maranhenses que atuavam tanto em aulas particulares quanto em escolas ludovicenses. Portanto, este trabalho ${ }^{3}$ visa analisar esses dois livros utilizados em espaços escolares para o ensino de música, no final do século XIX e início do XX, em São Luís do Maranhão, levando-se em consideração os conteúdos selecionados, a forma de apresentação, o público e os fins a que foram destinados. A obra de Perdigão (1869a), Principios elementares de musica, e a obra de Rayol (1902), Noções de musica, pertencem ao Acervo de Obras Raras da Biblioteca Pública Benedito Leite, em São Luís, sendo os únicos livros escolares de música encontrados até o momento.

Ainda são poucas as pesquisas realizadas a respeito desse tema no Maranhão, dentre elas citam-se a de Dantas Filho (2007, 2014), Cerqueira (2018), Gouveia Neto (2012) e Ferreira (2010). Dessa forma, há um vasto campo ainda a ser explorado, o que justifica a proposta deste artigo. Utiliza-se neste trabalho a pesquisa bibliográfica, com embasamento teórico em autores, como Bittencourt (2008), Magalhães (2011), Fagerlande (2011) os quais tratam dos livros escolares, e De Certeau (2012) que contribui para a compreensão das estratégias de imposição das regras, normas e táticas de apropriação dos sujeitos estudados, e a pesquisa documental, cujas fontes são os regulamentos da instrução pública, programas curriculares, legislação, mensagens dos Governadores, relatórios de instrução pública e jornais.

\section{Circulação de livros escolares à época}

Com a relevância dada no Império e, principalmente, na República ao livro escolar, este se tornou o impresso mais publicado pelas tipografias e o mais comercializado entre a população brasileira, superando os de ficção e os científicos. Bittencourt $(2008$, p. 83) ratifica essa informação quando afirma que "a circulação de livros escolares superava todas as demais

\footnotetext{
${ }^{1}$ Podem-se citar, dentre esses autores, Castro (2016, 2010), Castellanos (2017, 2016), Cury (2018), Duarte (2018), Soares (2018).

${ }^{2}$ Algumas citações utilizadas neste trabalho podem mencionar o termo manual escolar, livro de classe ou livro didático no lugar de livro escolar. Entretanto, apesar de mencioná-los, será adotado para os materiais selecionados nesta pesquisa o termo livro escolar, devido à sua forma e função.

${ }^{3}$ Este artigo integra as pesquisas desenvolvidas pelo Núcleo de Estudos e Documentação em História da Educação e das Práticas Leitoras/UFMA, que tem como foco a cultura material escolar, em especial os livros adotados nas escolas maranhenses do período imperial à Primeira República.
} 
obras de caráter erudito, possuindo um status diferenciado e, até certo ponto, privilegiado, considerando-se que a sociedade se iniciava no mundo da leitura". Em relação aos livros escolares de música utilizados no Brasil oitocentista, esses eram basicamente estrangeiros, em especial franceses e portugueses, pois os nacionais não eram bem conceituados por alguns educadores ${ }^{4}$. Nesse sentido, Bittencourt afirma (2008, p. 71) que "a aceitação e opção pela França entre setores de nossas camadas dominantes devem ser entendidas na trama de interesses econômicos e culturais estabelecida entre os dois países [França e Portugal]". Quanto à predominância da literatura portuguesa no Brasil até o século XIX, Fagerlande (2011, p. 41) relata que:

As razões tanto políticas quanto econômicas comprovam o vínculo forte entre os dois países; este elo é refletido também culturalmente, tanto pelo fato de que aqui as atividades musicais de origem europeia foram muito mais intensas do que em outras colônias portugueses, mas principalmente porque a maior parte das informações sobre música europeia no Brasil passava por Portugal.

Apesar dessa realidade, o espírito nacionalista defendia a produção de livros voltados à realidade brasileira. No final do século XVIII e no século XIX já circulavam obras didáticas nacionais de música, tais como: Arte da Muzica para uso da mocidade brasileira por hum seu patrício de 1823, de autoria anônima ${ }^{5}$; A arte de solfejar, de 1761, Muzico e moderno Systema para solfejar sem confusão, de 1776, ambos de Luís Alvares Pinto; Compêndio de música e método de pianoforte, de 1821, de Pe. José Maurício Nunes Garcia (FAGERLANDE, 2011; LANDI, 2006). Conforme Binder e Castagna (1998, p. 13), a primeira notícia "que sugere a presença de uma obra musical teórica no Brasil provém do inventário de Pascoal Delgado, que viveu em Santana do Parnaíba (SP) na primeira metade do século XVII". Nesse inventário foram avaliadas três obras de canto de órgão. Esses dois autores fazem a observação de que "somente os próprios tratados musicais brasileiros poderão nos informar quais obras teóricas foram realmente conhecidas pelos escritores brasileiros".

Para Morgado (2004), os livros escolares, na visão de alguns autores, não tratavam exclusivamente de conteúdos que faziam parte dos programas de ensino, mas também eram divulgadores de uma cultura, de uma ideologia, de valores em que viviam os escritores e/ou os leitores, podendo ser assim propagadores dessas expressões e terem o controle do ensino nas escolas. De Certeau (2012, p. 215) entende que a escritura "se torna poder nas mãos de uma 'burguesia' que coloca a instrumentalidade da letra no lugar do privilégio do nascimento, ligado a hipótese de que o mundo dado é a razão".

Tanto no Império quanto no início da República havia um propósito civilizatório no ensino formal, com princípios de moralidade. O modelo do ensino de música tradicional, que persistiu durante o século XX - e talvez até hoje -, enfatizando a sociedade europeia, tinha um caráter civilizatório e reprodutivo por parte da cultura dominante. A música utilizada como um meio civilizador atendeu aos ideais positivistas e republicanos, pois se buscava uma "melhor" música na visão de seus defensores, assim como um efeito moralizador, de ordem e progresso.

\footnotetext{
${ }^{4}$ Como exemplo desse posicionamento, pode-se citar o programa da aula de música da Escola Normal de São Luís, assinado em 12 de junho de 1890 por Luís Medeiros, lente da Cadeira, em que ele indicava alguns livros para serem usados nessa disciplina, a maioria em francês, e explicava essa preferência por não haver bons livros em português, em sua opinião (MEDEIROS, 1890).

${ }_{5}^{5}$ Conforme Landi (2006), alguns musicólogos brasileiros atribuem a autoria dessa obra a Francisco Manoel da Silva, autor do Hino Nacional Brasileiro.
} 
Esses discursos que elevavam a música à qualidade de civilizadora, de essencial a uma nação moderna (republicana), conseguiram seus objetivos, se observarmos os programas das Escolas Preliminares e Normal. Assim, a música, além de amenizar e equilibrar o ambiente escolar - a música higiênica - e de servir como educação sensorial, adquire uma posição de educadora moral e estética, indispensável para a civilização moderna, segundo os seus interlocutores. E ainda espetáculo escolar, servindo para irradiar e propagandear a escola republicana para toda a sociedade (MORILA, 2006, p. 87-88).

Sendo assim, os livros escolares para o ensino musical propagavam os ideais de cultura, sociedade e educação de cada época. Os textos escritos sempre sofreram controle ao longo da história, seja por conta dos poderes instituídos pela religião, pelo Estado, pelas famílias ou pela escola, os quais procuravam classificar o que seria recomendável ou não. De acordo com Bitencourt (2008), os livros utilizados nas escolas no período delimitado nesta pesquisa tinham que ser aprovados por órgãos do Governo, sendo sua vigilância executada pela Inspetoria de Instrução Pública de cada local. O professor poderia receber punição, admoestação, suspensão e multa, caso usasse algum livro dentre os proibidos. A Inspetoria intervinha pouco nas escolas particulares, embora estas não tivessem também permissão de usar obras não recomendadas. Nesse sentido, Chopin (2002) complementa quando afirma que o livro de classe se encontra na articulação entre a imposição dos programas oficiais e o discurso singular e concreto do professor em sala de aula, embora às vezes de natureza efêmera.

De Certeau (2012, p. 218), ao discutir sobre os elementos retirados ou acrescentados em um corpo, como ele chama o livro, acredita que essa atividade "remete a um código" e "mantém os corpos submetidos a uma norma". Isso acontece porque os corpos confirmam esses códigos, "pois onde é que há, e quando, algo do corpo que não seja escrito, refeito, cultivado, identificado pelos instrumentos de uma simbólica social?". Esse controle se enquadra dentro do processo civilizador, presente tanto no Império quanto na República do Brasil, determinando o que seria melhor para a população, assim como nos ideais positivistas, ao tentar eleger o que seria "bom" para o progresso e evolução do povo. Contudo, este autor discorre sobre a possibilidade de táticas desenvolvidas pelo povo, como uma reação à imposição das autoridades.

\section{Contexto dos impressos maranhenses}

Hallewell (2012, p. 182-185) declara que "em meados do século XIX, a produção de livros, como manifestação incidental da prosperidade maranhense, alcançou um alto padrão de excelência técnica e estética e volume suficiente para novamente chamar a atenção para as edições provinciais". O autor destaca dois editores desse período: Belarmino de Mattos (Typographia B. de Mattos) e José Maria Corrêa de Frias (Typographia do Frias), os quais eram "rivais amistosos, cujos contínuos esforços para superar as realizações um do outro foram a causa principal do desenvolvimento técnico e estético da produção de livros no Maranhão". Leão (2013) ressalta que, devido à qualidade da produção dessas duas tipografias, o preço ficou acessível e o comércio de livros aumentou, alcançando uma boa faixa da população, o que colaborou para o desenvolvimento das livrarias. Os jornais da cidade, como 
Publicador Maranhense, Liberal e o Diário do Maranhão, anunciavam a venda de livros escolares nas livrarias da capital ludovicense ou nas suas próprias tipografias.

Os dois livros escolares aqui analisados foram publicados pela Typographia do Frias, localizada em São Luís, e anunciados nos jornais dessa capital. Principios elementares de musica: em 10 lições, de autoria de Domingos Thomaz Vellez Perdigão, foi publicado em 1869. No livro O que se deve ler: Vade-Mecum Bibliographico (1922), de autoria de Domingos de Castro Perdigão, encontra-se a informação de que o livro de seu pai, Domingos Thomaz, possuiu duas edições, sendo a segunda publicada em 1900 por Luiz Magalhães \& Comp ${ }^{6}$. Quanto à divulgação de venda da segunda edição nos jornais (ver Figura 1), há referência em vários exemplares do jornal Diário do Maranhão, entre os dias 25 de abril e 29 de maio de 1900.

Figura 1: Anúncio do livro Princípios elementares de musica, de Perdigão.

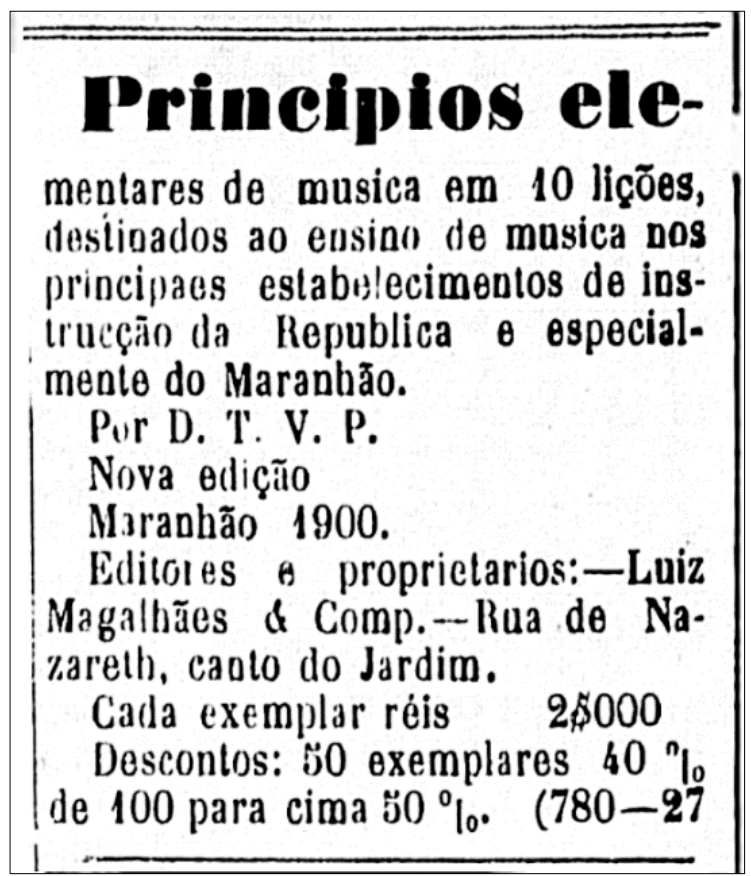

Fonte: Diário do Maranhão, 25 de abril de 1900.

O livro de Antonio Rayol, impresso em 1902 também pela Typographia do Frias, e intitulado Noções de musica: extrahidas dos melhores autores, possui algumas referências nos jornais locais. A primeira encontrada foi no Diário do Maranhão, de 25 de novembro de 1902 (p. 2): "Vai ser impresso um livrinho - ou arte de musica - para aprendizagem, trabalho preparado e compilado pelo Sr. Antonio Rayol, professor na Escola Normal e director da de musica do Estado. É uma boa noticia que damos, a quem se dedicar a aprender a divina arte". Nos exemplares desse mesmo jornal, de fevereiro a maio de 1903, localiza-se o anúncio da venda do livro de Rayol (ver Figura 2).

Em Pacotilha, de 20 de dezembro de 1902, foi divulgado o lançamento do livro Noções de musica. O Federalista de 5 de fevereiro de 1903 publicou um agradecimento a Rayol pelo envio de um exemplar de seu livro. Conforme Bittencourt (2008), essa era uma prática comum quando os próprios autores se responsabilizavam pela publicação de suas obras.

\footnotetext{
${ }^{6}$ Não foi identificada nenhuma referência à primeira edição desse livro nos jornais da época, uma vez que os exemplares da década de 1860 e do início de 1870 não estão mais disponíveis na Biblioteca ou no Arquivo Público do Maranhão.
} 
Figura 2: Anúncio do livro Noções de musica, de Rayol.

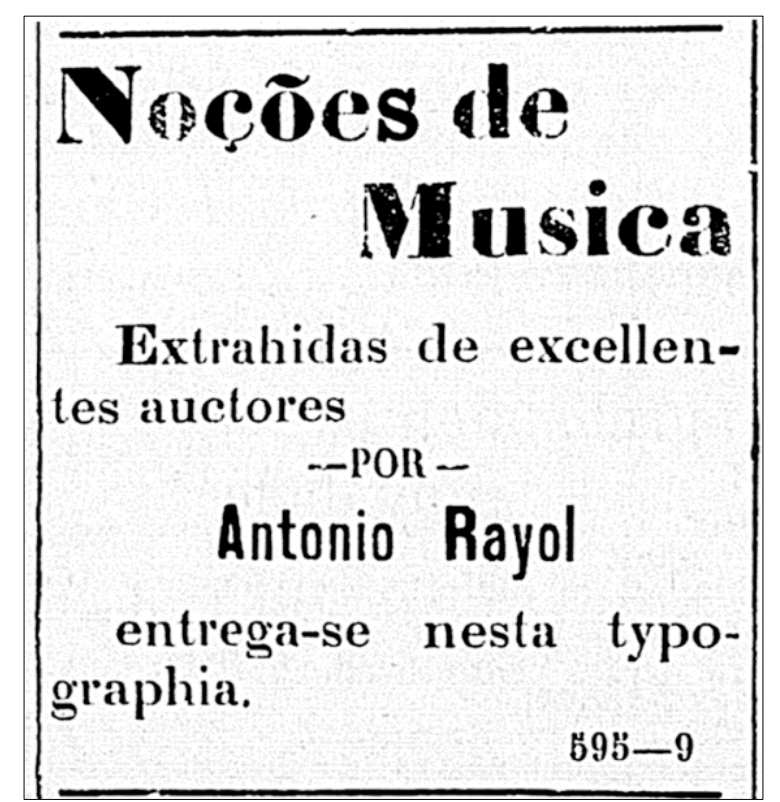

Fonte: Diário do Maranhão, 25 mar. 1903.

Esses jornais permitiram, juntamente com outras fontes, traçar os dados biográficos de Rayol e Perdigão. Desse último autor, poucas foram as informações encontradas. Os dados relatados a seguir foram obtidos em um texto de seu filho, Perdigão (1922a).

\section{Relatos biográficos a respeito de Perdigão e Rayol}

Domingos Thomaz Vellez Perdigão nasceu em 1842, em São Luís, sendo o segundo dentre os 21 filhos que seu pai, Domingos Feliciano Marques Perdigão, descendente de portugueses, teve em dois casamentos: o primeiro em 1840, com sua prima Sra. Ana Lourença Velêz de Carvalho (oito filhos), e o segundo com a Sra. Maria Luiza de Sá (treze filhos). Profissionalmente, é classificado como industrial e artista. Quanto a ser industrial, não se teve comprovação em nenhum documento pesquisado, mas, quanto a ser artista, foram encontradas atividades suas como professor de música (PERDIGÃO, 1922a).

No Almanak do Diário do Maranhão de 1879, encontra-se um anúncio de Domingos Thomaz como relojoeiro, colocando seus serviços à disposição da sociedade. Incluía nessa divulgação o conserto de máquinas elétricas, máquinas de coser, caixas de música, pianos, harmônios, realejos e instrumentos de cordas. Perdigão (1922b), na obra O que se deve ler: VadeMecum Bibliographico, informa que seu pai dava aulas de violino e piano, além de ser musicógrafo. No Colégio Perdigão, fundado por Domingos Feliciano, provavelmente em 1866, Domingos Thomaz ministrava aulas de piano e órgão, período em que publicou a obra Principios elementares de musica.

Um manuscrito intitulado Album de Musica também foi escrito por Perdigão (1869b), onde estão reunidas músicas de diversos gêneros, tais como valsas, polcas, masurcas, schottisch, quadrilhas, algumas para voz, outras para violão e outras somente com a melodia, sem especificação do instrumento para executá-las. Foi professor particular de rabeca na década de 1870, em São Luís, e faleceu no ano de 1899, em Portugal. Apesar de não serem obtidas maiores informações sobre a vida e obra desse músico, acredita-se que por fazer parte de uma família, cujo pai foi um renomado professor e diretor de escolas na capital maranhense, além de um músico dedicado a essa arte, Perdigão tenha tido uma vivência musical e uma educação que o possibilitou ter uma representatividade no meio artístico ludovicense. 
Antonio dos Reis Rayol, maranhense, era tenor, compositor, regente e violinista, filho de Augusto César dos Reis Rayol, descendente de espanhóis, poeta e funcionário do governo, e Leocádia A. Belo Rayol. Diferentes datas em torno do seu nascimento foram encontradas na literatura consultada. Jansen (1974), Grupo Nuclear Universitário (1972) e Cacciatore (2005) informam o ano de 1855 e Amaral (2001) em 23 de dezembro de 1864. Contudo, é deduzida ainda a data de 1863, a partir das reportagens sobre sua morte em jornais locais, pois fazem menção de que Rayol completaria 41 anos de idade em 23 de dezembro de 1904.

Influenciado pelas inúmeras companhias líricas que passaram pelo estado, Rayol se interessou pelo canto e ganhou uma bolsa de estudos para a Itália, patrocinada pelo Conde de Leopoldina $^{7}$. Em sua estada na Europa, participou do concurso de canto Giuseppe Verdi, durante as comemorações ao centenário de Giácomo Rossini, ganhando o quinto lugar (JANSEN, 1974; CACCIATORE, 2005). Residindo na Itália, compôs e regeu, dentre outras obras musicais, a Missa Solene, que se tornou a mais famosa de sua carreira. Enviou a partitura dessa missa para Carlos Gomes, que, em agradecimento, retribuiu com o envio da partitura de sua obra Condor, com dedicatória para Rayol.

De volta ao Brasil, participou de vários concertos, foi professor de música no Rio de Janeiro, na Bahia, e, em 1900, residindo em São Luís, lecionou no Liceu Maranhense, na Escola Normal e na Aula Noturna de Música ${ }^{8}$. No ano de 1901 foi nomeado diretor da recém-formada Escola de Música ${ }^{9}$. Compôs muitas obras de vários gêneros, dentre eles a música do Hino do Maranhão. Conforme noticiado no jornal local Pacotilha, de 22 de novembro de 1904, Antonio Rayol faleceu na data de 21 de novembro desse ano, às $23 \mathrm{~h} 30 \mathrm{~min}$, embora conste a data de $22 \mathrm{de}$ novembro no Livro de Óbito da Freguesia de Nossa Senhora da Conceição da Capital (MARANHÃO, 1894-1910). A sua morte teve uma grande repercussão e no seu enterro muitas pessoas prestaram suas últimas homenagens àquele que foi consagrado pelos maranhenses como o primeiro tenor ${ }^{10}$ do Brasil. Durante a pesquisa, identificou-se nos jornais ${ }^{11}$ locais e nacionais a divulgação da imagem de Rayol abrangendo aspectos sociais, culturais, profissionais e pessoais da sua vida. Não se sabe se esse espaço era pago ou concedido por amizade, mas foi importante para a construção de sua legitimidade.

Pela documentação pesquisada, constatou-se que Perdigão e Rayol foram figuras influentes e atuantes em seu tempo, e frequentavam os lugares em que a elite circulava, tanto a econômica quanto a intelectual. Quanto à participação em festas populares, há relatos nos jornais da presença de Rayol em bailes de Carnaval. Pela genealogia apresentada, não eram de uma família de grandes posses, embora possam ter adquirido bens materiais como músicos e professores. Supõe-se que o patrimônio cultural foi provavelmente o que lhes permitiu circular pelo meio social e dar-lhes uma representatividade perante a sociedade maranhense. Esse fato proporcionou a ambos os músicos a oportunidade de elaborarem um livro escolar, dentre, é claro, tantas outras atividades e feitos.

\footnotetext{
${ }^{7}$ Meirelles (1972) informa que o Conde de Leopoldina era o empresário Henrique Lowndes, e Ferreira (2010) complementa que o mesmo conseguiu sua fortuna por meio de empreendimentos comerciais e ações especulativas, sendo importante no cenário econômico do Brasil no final do oitocentos e início do século XX. Também era filantropo, e dentre suas ações ele concedia bolsas de estudos para jovens artistas.

${ }^{8}$ A Aula Noturna, fundada em 1900 em São Luís, foi uma instituição pública de ensino de música com poucos recursos frente ao que Rayol almejava. Funcionou somente durante um ano, sendo extinta com a criação da Escola de Música.

${ }^{9}$ A Escola de Música, criada em 1901 e extinta em 1912, teve como diretores dois renomados músicos maranhenses: Antonio Rayol, como primeiro diretor, e João Nunes, como segundo. Durante os anos de funcionamento, a direção da escola não pôde efetivar a contratação do quantitativo docente necessário para oferecer o número pretendido de cadeiras, apesar da significativa quantidade de alunos matriculados, da grande demanda existente e dos recitais e concertos realizados. Para maiores informações sobre o ensino de música no Liceu Maranhense, na Escola Normal, na Aula Noturna e na Escola de Música, ver Salomão (2016).

${ }^{10}$ No Grupo Nuclear Universitário (1972), é relatado que Rayol ganhou o primeiro lugar em um concurso nacional de canto ainda jovem, por isso ser chamado de primeiro tenor brasileiro.

${ }^{11}$ Gouveia Neto (2012) discorre em seu trabalho sobre a vida profissional de Antonio Rayol na segunda metade do oitocentos em São Luís, a partir do jornal $A$ Luta.
} 


\section{Análise das obras selecionadas}

A análise das obras centrou-se nos conteúdos, na forma de apresentação, no público e nos fins a que foram destinadas, nesse caso usando o termo "objetivos". Em Magalhães (2011, p. 16), é possível encontrar alguns desses aspectos entre os parâmetros que constituem a estrutura analítica, utilizada por Anne-Marie Chartier em sua pesquisa "sobre a articulação entre o suporte livro e a racionalidade pedagógica". São eles:

A forma como o manual se apresenta a si próprio (por exemplo, "manual para" determinada classe/ano, aprovado por, edição ampliada, ilustrado, etc.); a configuração de livro; os conteúdos; a representação da cena escolar; os públicos a que se destina; o método pedagógico-didáctico que apresenta.

A obra Principios elementares de musica, de Perdigão, foi publicada com a finalidade de ser usada nas aulas de música do Colégio Perdigão. No entanto, conforme a propaganda nos jornais (ver Figura 1), a segunda edição, lançada em 1900, já ampliava os fins pretendidos, destinando-os ao ensino de música dos principais estabelecimentos de Instrução da República e, especialmente, do Maranhão ${ }^{12}$. Os conteúdos desse livro escolar são expostos no Quadro 1. Antes de adentrar nas lições, Perdigão (1869a, p. 5) define música como sendo "a arte de combinar os sons pela sua elevação e duração", uma definição semelhante às outras encontradas em livros que circulavam em sua época.

Quadro 1: Conteúdos abordados no livro de Perdigão

\begin{tabular}{|c|c|c|c|}
\hline LIÇÃO & TÍTULO & ASSUNTO & PÁGINA \\
\hline $1^{\mathrm{a}}$ & Das linhas e espaços & $\begin{array}{l}\text { Pauta; linhas suplementares superiores e } \\
\text { inferiores. }\end{array}$ & $5-6$ \\
\hline $2^{\mathrm{a}}$ & Das figuras e seus valores & $\begin{array}{l}\text { As sete figuras, suas pausas e valores } \\
\text { correspondentes entre elas; ponto de } \\
\text { aumento; tresquialtera e sexquialtera } \\
\text { (diminuição). }\end{array}$ & $6-8$ \\
\hline $3^{\mathrm{a}}$ & Dos signos & As sete notas musicais. & $8-9$ \\
\hline $4^{\mathrm{a}}$ & Das claves & Clave de sol, dó e fá. & $9-10$ \\
\hline $5^{\mathrm{a}}$ & Do compasso e dos tempos & $\begin{array}{l}\text { Compasso; Os algarismos do tempo do } \\
\text { compasso; Compasso binário, ternário e } \\
\text { quaternário; Regência dos três tipos de } \\
\text { compassos. }\end{array}$ & $11-13$ \\
\hline $6^{\mathrm{a}}$ & Dos signaes d'alteração & $\begin{array}{l}\text { Sustenido; bemol e bequadro; dobrado } \\
\text { sustenido e dobrado bemol. }\end{array}$ & $14-15$ \\
\hline $7^{\mathrm{a}}$ & Dos tons & $\begin{array}{l}\text { Intervalo entre as notas de uma escala; } \\
\text { Tons maiores e menores com sustenidos } \\
\text { e com bemóis (escalas). }\end{array}$ & $15-17$ \\
\hline $8^{\mathrm{a}}$ & Das notas de ornamento & Apojectura; Grupo; Trinado; Mordente. & $18-19$ \\
\hline $9^{a}$ & Da syncopa e ligadura & Sincope e ligadura. & $19-20$ \\
\hline $10^{\mathrm{a}}$ & De alguns signaes acessórios & $\begin{array}{l}\text { Firmata-Ponto d'orgão-caldeirão, Da } \\
\text { cappo, Al Segno, Intensidade (p, f, pp, } \\
\text { ff), crescendo e diminuindo, articulação, } \\
\text { abreviatura, bis, casa } 1 \text { e } 2 \text {, andamento } \\
\text { ou movimento. }\end{array}$ & $20-23$ \\
\hline
\end{tabular}

Fonte: Quadro elaborado a partir da obra Principios elementares de musica de Perdigão (1869a).

\footnotetext{
${ }^{12} \mathrm{O}$ exemplar da primeira edição, que se encontra na Biblioteca Pública Benedito Leite, está em fase inicial de deterioração, mas já foi digitalizado. Como não se teve acesso à segunda edição, os comentários feitos aqui se referem somente ao impresso encontrado.
} 
Nessas lições apresentadas por Perdigão, pode-se observar que os temas são explicados de maneira bem simplificada, sem adentrar muito nas definições, tampouco na origem histórica de cada conteúdo. Da mesma forma, não abrange muitos assuntos, tratando dos mais básicos, necessários à leitura e à escrita musical tradicional. Nos livros de ensino musical anteriores e posteriores ao de Perdigão, mas coincidindo com o período de sua circulação, foi observada a existência de várias obras nesse formato simplificado, chamadas, muitas vezes, de artinhas. Acredita-se que o livro de Perdigão, nesse contexto, possa ser chamado de uma artinha. No entanto, mesmo sendo conciso, teve duas edições, o que pode sugerir uma considerável circulação no período e uma relevância no ensino musical.

Em todas as lições, foram encontrados exemplos da grafia musical tradicional, os quais ilustram os assuntos apresentados e possibilitam um entendimento maior dos conteúdos. Bittencourt (2008, p. 197) informa que essa prática de ilustrar livros escolares foi comum durante o século XIX. "As ilustrações dos livros didáticos favoreciam, portanto, de acordo com as concepções de aprendizado, uma forma de o aluno ter contato com situações mais concretas não apenas para crianças, mas também para jovens”. Ao fim de cada lição, Perdigão elaborou um questionário. Abaixo, segue a transcrição das questões da primeira lição como exemplo do modelo usado para todas as outras lições do livro.

1. O que é música?

2. Como se contam as linhas?

3. Como se contam os espaços?

4. Que nome se dá às cinco linhas?

5. Além dessas cinco ordinárias, não há outras?

6. Por que se chamão as cinco linhas ordinarias?

7. Como se chamão as linhas além das ordinarias?

8. Por que se chamão suplementares ou acidentaes, as linhas, que se acrescentão por baixo ou por cima das linhas ordinárias?

9. Como se chamão as suplementares que se acrescentão por cima?

10. Que nome se dá as suplementares que se acrescentão por baixo das linhas ordinárias?

A partir da análise dos conteúdos e dos exercícios propostos, percebe-se uma prioridade dada aos assuntos teóricos, da escrita e da leitura tradicional, para aquisição de alguns conhecimentos de música, como o autor se propõe, denotando uma concepção mais tradicional de ensino, em que esses aspectos da teoria são relevantes antes da parte prática. Bittencourt (2008) reforça a ideia de que os exercícios e as ilustrações das obras didáticas demonstram qual metodologia de ensino essa obra pode conter. Nesse caso, priorizando-se a memorização por meio do questionário, observa-se novamente uma metodologia mais tradicional, comum ao ensino musical da época do autor.

Perdigão deixou claro desde a contracapa de seu livro (ver Figura 3) que o mesmo era destinado à aula de música do Colégio Perdigão, uma instituição privada e voltada principalmente aos meninos, que oferecia o ensino primário e secundário em regime de internato, semi-internato e externato. 
Figura 3: Livro Principios elementares de musica

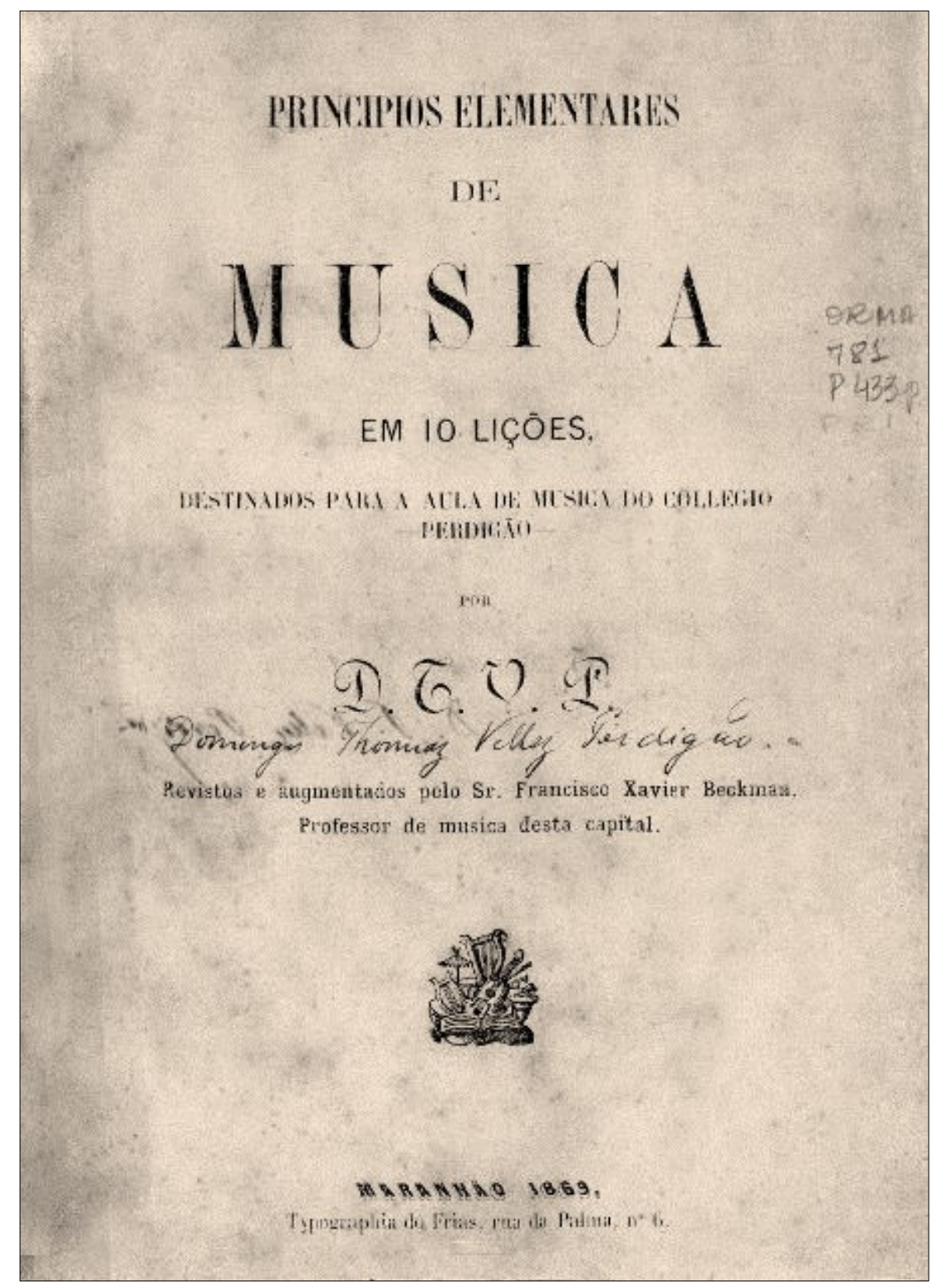

Fonte: Perdigão (1869a).

Quanto à finalidade da obra, o autor explica na introdução que:

Vendo a necessidade que havia d'uns princípios fáceis para qualquer adquirir alguns conhecimentos de musica; dediquei-me ao trabalho de arranjar estes Princípios Elementares para a aula de musica do Collegio Perdigão de meu Pai; o Snr. Dr. Domingos Feliciano Marques Perdigão: depois de ter lido cuidadosamente alguns tratados sobre a matéria; e com alguma pratica, que tenho adquerido ensinando o pouco que sei desta bella arte, organizei-os em dez lições, simplificando tudo o mais que me foi possível. Todavia não pude deixar de mostrar este meo pequeno trabalho ao Sr. Francisco Xavier Beckman, meu mestre de musica, e pedir que o corrigisse; ao que elle anuiu de bom grado, não só fazendo algumas emendas, como também augmentando algum tanto; do que me confesso grato (PERDIGÃO, 1869a, p. 3). 
Ele encerrou essa parte deixando explícito o objetivo da publicação do livro: “o aproveitamento dos discípulos do Collegio, e o seu adiantamento no mais curto espaço de tempo possível. Se o resultado for tal, como espero, terei conseguido o fim que pretendo, e ficarão os meus desejos plenamente preenchidos" (PERDIGÃO, 1869a, p. 3). Sendo assim, Perdigão não teve pretensões de escrever um livro escolar volumoso, mas sim um material que pudesse ser de fácil entendimento para os alunos e conseguisse um resultado satisfatório ao que a escola se propunha, em um período não muito longo. Chopin $(2002$, p. 21) expõe que "o manual pode divulgar discursos muito diferentes, segundo as épocas e/ou os países: pode ser o produto da livre concorrência entre as empresas privadas [...]; pode, ao contrário, [...] representar e desenvolver, [...] o discurso da instituição".

Como já mencionado, os conteúdos dos livros escolares, muitas vezes, tratavam dos mesmos conteúdos dos programas de ensino. Contudo, não foi encontrada, nesta pesquisa, a relação dos conteúdos de música que, segundo os programas de ensino do governo, deveriam ser trabalhados em sala de aula no período de Perdigão. Ainda assim, por meio dos assuntos tratados em seu livro, é possível ter a ideia do que era levado em consideração pelos professores como relevante ao ensino de música, e que, consequentemente, foi utilizado no Colégio Perdigão.

Na obra Noções de musica: extrahidas dos melhores auctores (1902), os assuntos tratados por Rayol (Quadro 2) abrangem vários temas e explicações históricas, mesmo que não sejam muito extensas. Para Dantas Filho (2007), todo o conteúdo do livro poderia ser agrupado nos seguintes segmentos: elementos introdutórios, formação básica e elementos complementares de formação musical.

Quadro 2: Conteúdos abordados no livro de Rayol

\begin{tabular}{|l|l|c|}
\hline \multicolumn{1}{|c|}{ TÍTULO } & \multicolumn{1}{|c|}{ ASSUNTO } & PÁGINA \\
\hline $\begin{array}{l}\text { Música, sua origem e } \\
\text { importância }\end{array}$ & $\begin{array}{l}\text { Definição de música, importância da música } \\
\text { dentre as artes, e algumas características da } \\
\text { música em diferentes períodos. }\end{array}$ & $11-14$ \\
\hline Divisão real da música & $\begin{array}{l}\text { Música teórica e prática; melodia, harmonia e } \\
\text { ritmo. }\end{array}$ & $14-18$ \\
\hline Subdivisão & $\begin{array}{l}\text { A subdivisão da música (de salão, militar, } \\
\text { religiosa, etc.). }\end{array}$ & $18-20$ \\
\hline Som & Definição de som, sua classificação, as vibrações. & $20-21$ \\
\hline Intervalos & Definição e classificação dos intervalos. & 22 \\
\hline Acústica & Definçãa e função de acústica. & 22 \\
\hline Diapasão & Definção de diapasão. & 23 \\
\hline Pauta ou pentagrama e espaços & Linhas e espaços da pauta, linhas suplementares. & 23 \\
\hline Das notas e sua origem & $\begin{array}{l}\text { iita as notas musicais e a origem da sua } \\
\text { nomenclatura. }\end{array}$ & $24-25$ \\
\hline Claves (sua origem) & Explica a origem e tipos de claves. & 26 \\
\hline Accidentes & Explica a função e os tipos de acidentes. & 26 \\
\hline Compasso & Definição e tipos de compasso. & $26-27$ \\
\hline Modos & Definição e tipos de modos. & 28 \\
\hline Quiálteras & Definição de quiáltera. & 28 \\
\hline Signos & Definçção de signos. & 28 \\
\hline Generos & Sons diatônicos, cromáticos e enarmônicos. & 29 \\
\hline Systemas & Explicação de sistemas. & 29 \\
\hline Syncopes & Significado e tipos de sincopes. & 30 \\
\hline Tempos & $\begin{array}{l}\text { Explica o tempo correto para a execução da } \\
\text { música. }\end{array}$ & $30-31$ \\
\hline
\end{tabular}




\begin{tabular}{|l|l|c|}
\hline \multicolumn{1}{|c|}{ TÍTULO } & \multicolumn{1}{|c|}{ ASSUNTO } & PÁGINA \\
\hline Contratempos & Definição de contratempo. & 32 \\
\hline Tom & $\begin{array}{l}\text { Explicação e classificações de tom (maior, menor, } \\
\text { etc.). }\end{array}$ & $32-33$ \\
\hline Commas & Definição de coma. & 33 \\
\hline Intonação & Definição de entonação. & 34 \\
\hline Cantar & Definição e regras para sua execução. & $34-35$ \\
\hline Solfejar & Definição de solfejo. & 35 \\
\hline Ler música & $\begin{array}{l}\text { Definição (leitura métrica) e explicação de como } \\
\text { executar }\end{array}$ & $35-36$ \\
\hline Respiração & Definição de respiração. & 36 \\
\hline Transposição & Função da transposição e sua execução. \\
\hline Escala (sua etimologia) & Definição e explicações de escalas. & 37 \\
\hline Grammatica de musica & Definição e regras para sua execução. & 37 \\
\hline Lingua musical & Gramática, poesia e retórica. & 39 \\
\hline Composição & Definição de composição. & 39 \\
\hline Vozes & $\begin{array}{l}\text { Definição, classificação das vozes e exemplos de } \\
\text { cantores renomados. }\end{array}$ & $40-45$ \\
\hline $\begin{array}{l}\text { Explicação: sobre musicas, } \\
\text { instrumentos e mais algumas } \\
\text { cousas uteis. }\end{array}$ & $\begin{array}{l}\text { Diferentes gêneros musicais, instrumentos musicais, } \\
\text { conservatórios, outros termos. }\end{array}$ & $45-56$ \\
\hline
\end{tabular}

Fonte: Quadro elaborado a partir da obra Noções de musica de Rayol (1902).

A falta de ilustrações da grafia musical é outro diferencial em relação à obra de Perdigão. Em seu livro, Rayol declara que o trabalho era incompleto, tendo que supri-lo com a sua prática, mas esperava que os leitores entendessem as falhas. $\mathrm{O}$ autor esclarece que não havia tipografia musical, e pedia que os leitores lembrassem que o livro era exclusivamente para seus alunos. Como ele sugere, a ausência de exemplos musicais teria sido por falta de recursos tipográficos da época, apesar de que, aproximadamente, 34 anos antes, o livro de Perdigão, impresso pela mesma tipografia, a do Frias, tinha vários exemplos ilustrados. Hallewell (2012) informa que a qualidade dos impressores no Maranhão era superior ao trabalho de qualquer outro realizado pela corte. Bittencourt (2008) relata que O Livro do povo, impresso por Frias em 1861, tinha muitas páginas ilustradas. Provavelmente, no período de Rayol, a tipografia não apresentava mais as mesmas condições anteriores de impressão.

Outro ponto observado corresponde ao fato de Noções de musica não ter exercícios sobre os temas a serem estudados. Percebe-se também a introdução dos assuntos com os pontos da grafia musical, como pauta, figuras, claves, abordados somente na oitava parte da obra, além de aspectos relacionados à percepção, como o som, a acústica e os intervalos, temas relevantes de serem abordados antes de se adentrar a parte da escrita e da leitura. Da mesma forma que Perdigão, nas páginas iniciais, Rayol deixa claro o fim de seu livro e a quem se destina.

As noções que me dei ao trabalho de redigir para iniciar meus discípulos no mysterioso alcance da Musica, e que agora ouso publicar sob o título de - Noções de Musica -, não são mais que uma ligeira compilação de quanto achei bastante esthetico e indispensável para o fim a que me propuz (RAYOL, 1902, p. 6).

Sendo professor da Escola Normal e da Escola de Música, Rayol pretendia que seu trabalho atendesse às necessidades dos alunos dessas instituições (ver Figura 4). No entanto, a divulgação do livro e os anúncios de venda presentes nos jornais locais da época podem ter favorecido uma abrangência maior de público fora do âmbito das escolas propostas. 
Figura 4: Dedicatória do Livro Noções de musica

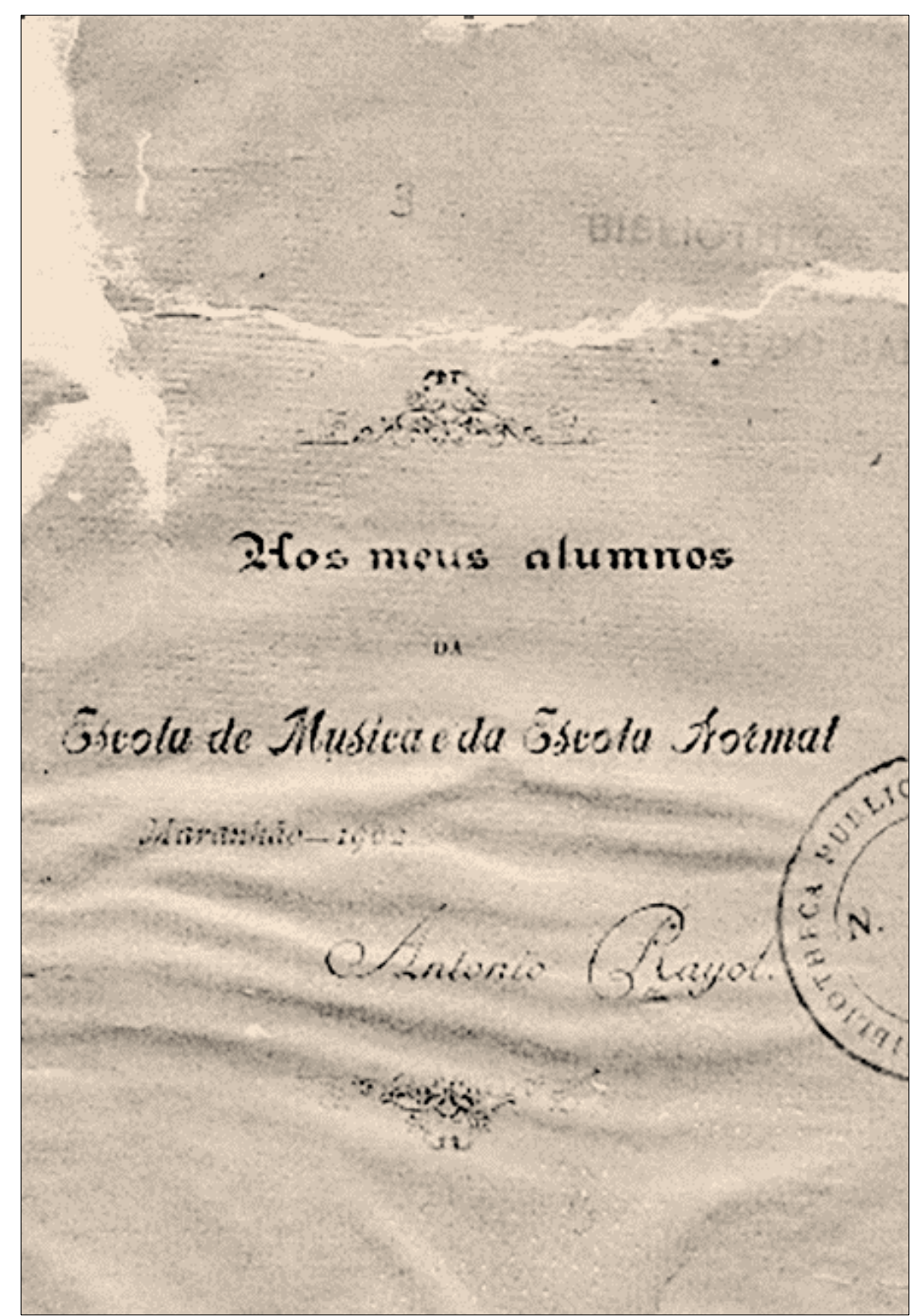

Fonte: Rayol (1902).

Rayol (1902, p. 6) declarava a sua missão por meio de uma frase de Mr. Fetis: "Propagar a arte que cultivo - eis a minha vocação e não lhe posso resistir - tudo que se dirige a esse fin é essencialmente bom". Após essa afirmação, o autor escreveu uma advertência e, em seguida, um texto aos leitores. Esses textos introdutórios existentes nos livros, tais como prefácio, advertência e introdução, eram um diálogo em que o autor explicava ao professor suas concepções e como seu livro deveria ser utilizado em sala de aula (BITTENCOURT, 2008).

Este trabalho é destinado a facilitar o ensino pela arte de Leopoldo Miguez onde são encontradas as demais explicações necessárias ao estudo theorico elementar. O estudo de solfejo deve ser feito pelos Compendios de Ignacio Porto Alegre, adoptados no Instituto Nacional de Musica do Rio de Janeiro e pelo Compendio de Claude Auge [sic] das escolas de Pariz (RAYOL, 1902, p. 7). 
O livro de Rayol não possui todos os conteúdos discriminados nos programas de ensino encontrados para a Escola Normal e Escola de Música ${ }^{13}$, mas os livros recomendados por ele para serem trabalhados conjuntamente em sala de aula: o de Miguez (19--), o de Augé (1896) e o de Porto-Alegre (189-), complementam os assuntos requeridos por esses programas. Ainda enquanto diretor da Aula Noturna, Rayol discorreu sobre as mudanças necessárias ao ensino de música na capital, expondo sua opinião sobre a situação encontrada: "A musica precisa ser desenvolvida entre nós, pois de certo tempo para cá nota-se grande atraso especialmente no systema de ensino, despresando-se completamente o estudo de solfejo e leitura rythmica" (MARANHÃO, 1901, p. 5). Por meio dessa observação, justifica-se sua preocupação e interesse em adotar dois livros de solfejo em sala de aula. O livro de Augé (1896) também continha alguns exercícios de leitura métrica (leitura rítmica). Esse interesse manteve-se no programa de ensino da Escola Normal de 1916, que, dentre os compêndios recomendados, citava o de Miguez (19--) para teoria musical e o de J. Arnoud para solfejo (CONGRESSO PEDAGÓGICO, 1922).

Os dois autores maranhenses fizeram uso de autores nacionais e estrangeiros para um embasamento teórico. Perdigão (1869a), na introdução, explicou que leu outros tratados de música, mas sem especificá-los, e aliou a isso sua experiência como docente, mesmo reconhecendo ser pouco o seu saber. Além disso, submeteu o trabalho à avaliação do seu professor Francisco Xavier Beckman, que, além de corrigi-lo, colaborou com o acréscimo de alguns pontos. Rayol (1902), por sua vez, na parte dedicada "aos leitores", referiu-se duas vezes à consulta feita a outros autores. Na primeira, ele reconheceu que carecia de habilitações para produzir uma obra e que contava com os recursos dos gênios transcendentes, dos quais conseguiu compreender as suas apreciações, expondo-as como se acham, esperando que seus alunos aproveitassem as mesmas sensações que ele obteve. Na segunda, declarou confiar nas autoridades que consultou: Savard, Choron, Fayolle, Artusi, Rousseau, Cattaneo e Rafael Machado, de cujo dicionário copiou a maioria das definições. O próprio título da obra já esclarece essa consulta, pois inclui a palavra extraída, Noções de musica: extrahidas dos melhores auctores. A menção da utilização de outros autores permite confirmar a observação antes citada de Binder e Castagna (1998), de que, a partir do próprio texto escrito, é possível descobrir quais obras realmente foram conhecidas pelos escritores brasileiros.

Como não se teve acesso aos outros livros que Rayol consultou, não se pode afirmar o limite entre as citações dos autores e o que ele complementou. Provavelmente, a parte de canto, onde ele detalha a postura física e o uso do aparelho respiratório para que o executor alcance melhor resultado na emissão da voz, deve ter sido o relato de sua prática como tenor lírico, que era a sua especialidade. Observa-se que, apesar de Perdigão e Rayol se utilizarem de outros autores, a prática deles se mantém presente nos seus discursos, pois as "táticas formam um campo de operações dentro do qual se desenvolve também a produção da teoria. [...] A narrativização das práticas seria uma 'maneira de fazer' textual, com seus procedimentos e táticas próprias" (DE CERTEAU, 2012, p. 141).

Assim, percebem-se certas semelhanças entre os livros estudados. Observa-se esse pressuposto quando foram analisados alguns aspectos, como os conteúdos trabalhados, o provável método de ensino adotado, a difusão da cultura europeia. Nota-se, ainda, a representação que eles nos dão sobre o contexto do ensino de música à época. Mais uma vez, tem-se o olhar sobre essas fontes, elaborando uma narrativa que tenta representar o contexto do período, a partir de outras narrativas e representações. Como exposto neste artigo, a utilização dos livros escolares no ensino público e particular deveria ser aprovada por órgãos do Governo. Não foi encontrado em nenhum documento referência de autorização do uso dos livros de Perdigão e Rayol, mas acredita-se que eram aprovados por esse órgão, uma vez que o de Rayol era aplicado nas Escolas Normal e de

\footnotetext{
${ }^{13}$ O programa de ensino da Escola Normal encontrado refere-se ao ano de 1890, apresentado em Medeiros (1890). O da Escola de Música foi publicado no Diário do Maranhão de 10 de maio de 1901.
} 
Música, ambas instituições pertencentes ao Estado, e o de Perdigão foi reproduzido em duas edições, sendo uma autografada e doada por seu filho, Domingos Perdigão, à Biblioteca Pública do Estado, em 1899.

Embora somente dois livros escolares de música de autores maranhenses foram encontrados, não se pode desconsiderar a existência de outros, já que várias escolas ofereciam o ensino de música e havia muitos professores particulares. Elpídio Pereira, compositor e violinista maranhense, em seu livro A música, o consulado e eu, relata ter elaborado um tratado de teoria musical, coligando à Artimanha de música, de Rossini (PEREIRA, 1957). Diante dessa afirmação e da possibilidade da existência de outros materiais, indaga-se: por que são mencionados nas fontes pesquisadas somente os livros de Rayol e de Perdigão?

Provavelmente, um dos fatores pode ser a relevância musical de Rayol, assim como as instituições em que foi professor, ou seja, o Liceu, a Escola Normal e a Escola de Música. Perdigão, por outro lado, era de uma família reconhecida no meio educacional, pois seu pai era professor e fundador de duas escolas e um de seus filhos foi diretor da Biblioteca Benedito Leite, o que pode ter possibilitado a divulgação e a manutenção do seu livro. Em relação a essas táticas empregadas, vencendo-se, nesse caso, a barreira do tempo, cita-se De Certeau (2012, p. 97-98), ao expor sobre as "maneiras de pensar as práticas cotidianas dos consumidores" e como essas maneiras parecem "corresponder às características das astúcias e das surpresas táticas", quais sejam os 'gestos hábeis do 'fraco' na ordem estabelecida pelo 'forte', arte de dar golpes no campo do outro, astúcia de caçadores, mobilidade nas manobras, operações polimórficas, achados alegres, poéticos e bélicos".

\section{Considerações finais}

A recomendação para o material escolar impresso utilizado em sala de aula se destinava, preferencialmente, aos livros estrangeiros, em especial os portugueses e franceses, pois, apesar de haver um movimento em prol de obras nacionais, muitos professores não davam a elas o devido crédito. Essa preferência fazia parte de um discurso da elite em prol de interesses econômicos e culturais, e pelo processo civilizatório, tendo como base o modelo europeu, como evidencia Bittencourt (2008). Dentre essas obras nacionais publicadas, têm-se os livros escolares dos maranhenses Domingos Thomaz Vellez Perdigão e Antonio dos Reis Rayol. Observou-se neste trabalho uma mudança na preferência dos livros de música recomendados para a Escola Normal entre as décadas de 1890, 1900 e 1910, quando os primeiros eram essencialmente estrangeiros e, nas décadas seguintes, já havia na lista a presença de autores nacionais.

A análise de Principios elementares de musica: em 10 Lições, de autoria de Perdigão, e de Noções de musica: extrahidas dos melhores auctores, de Rayol, considerou os conteúdos, a apresentação, o público e os fins a que se destinavam. O livro de Perdigão, quantos aos conteúdos, é bem sucinto, abordando os elementos básicos da música em dez lições. O autor apresentou desde a primeira lição conteúdos da teoria musical, em uma sequência progressiva de assuntos (do particular para o geral), com questionários que favoreciam a memorização, seguindo uma concepção mais tradicional de ensino, mesmo sendo para uma escola regular (ensino primário e secundário), ou seja, sem pretensões profissionalizantes. Utilizou-se de uma abordagem mais simples, com ilustrações, para um fácil entendimento, de modo que os alunos do Colégio Perdigão adquirissem conhecimentos de música necessários à execução de uma leitura no estudo dos instrumentos em curto período de tempo.

O livro de Rayol, por sua vez, continha mais conteúdos do que o anterior, sendo mais aprofundado nas explicações e origem dos temas, embora sem ilustrações e sem iniciar diretamente com assuntos da grafia musical. Por ser destinado a duas escolas profissionalizantes, a Escola de Música e a Escola Normal, Rayol procurou aprofundar-se mais nos assuntos tratados. Da mesma forma que o livro de Perdigão, denota uma concepção mais tradicional, pois a Escola 
de Música ensinava, em primeiro lugar, a teoria e depois o instrumento, ou seja, o livro se dispunha a esse fim. Acredita-se que os dois livros analisados foram relevantes para a constituição do ensino de música no Maranhão no oitocentos e no início da República.

\section{Referências}

ALMANAK DO DIÁRIO DO MARANHÃO PARA O ANO DE 1879: $2^{\circ}$ anno. São Luís: Frias, 1879.

AMARAL, Simão Pedro. Canto lírico no Maranhão: descontinuidade de uma arte não consolidada (Trabalho de Conclusão de Graduação). Universidade Federal do Maranhão, São Luís, 2001.

AUGÉ, Claude. Le livre de musique. 56. ed. Paris: Librairie Larousse, 1896.

BINDER, Fernando; CASTAGNA, Paulo. Teoria musical no Brasil: 1734-1854. In: SIMPÓSIO LATINO-AMERICANO DE MUSICOLOGIA, 1, 1997, Curitiba, PR. Anais eletrônicos... (p. 198217). Curitiba, PR: Fundação Cultural de Curitiba, 1998.

BITTENCOURT, Circe. Livro didático e saber escolar: 1810-1910. Belo Horizonte: Autêntica, 2008.

CACCIATORE, Olga Gudolle. Dicionário biográfico de música erudita brasileira: compositores, instrumentistas e regentes, membros da ABM (inclusive musicólogos e patronos). Rio de Janeiro: Forense Universitária, 2005.

CASTELLANOS, Samuel Luis Velázquez. O livro escolar no Maranhão Império (1822-1889). São Luís: EDUFMA; Café \& Lápis, 2017.

. A circulação do "livro de classe" francês no Maranhão Império. In: CASTELLANOS, S.; CASTRO, C. (Org.). Livro, leitura e leitor: perspectiva histórica. São Luís: Café \& Lápis; EDUFMA, 2016.

CASTRO, César Augusto (Org.). Livro, leitura e leitor: perspectiva histórica. São Luís: Café \& Lápis; EDUFMA, 2016.

. Leituras, impressos e cultura escolar. São Luís: EDUFMA, 2010.

CERQUEIRA, Daniel Lemos. Pesquisa Artística sobre o piano no Maranhão. Trabalho de ensaio II. Rio de Janeiro: PPGM/UNIRIO, 2018.

CHOPIN, Alain. O historiador e o livro escolar. História da Educação, ASPHE/FaE/UFPEL, Pelotas, v. 6, n. 11, p. 5-24, jan./jun. 2002. Disponível em: https://seer.ufrgs.br/asphe/article/view/30596. Acesso em: 25 fev. 2015.

CONGRESSO PEDAGÓGICO. São Luís: Imprensa Oficial, [Trabalhos apresentados...], 1922.

CURY, Cláudia Engler. Manuais de civilidade na imprensa da Paraíba oitocentista (1862-1886). In: CASTRO, César Augusto; CASTELLANOS, Samuel Luis Velázquez (Org.). História da escola: métodos, disciplinas, currículos e espaços de leitura. São Luís: EDUFMA; Café \& Lápis, 2018.

DANTAS FILHO, Alberto P. A grande música do Maranhão Imperial: estudo histórico musicológico a partir do acervo Musical de João Mohana. Teresina: Haley, 2014. 
. Dois métodos musicais da São Luís Imperial (1869/1902). In: OLIVEIRA, Alda; CAJAZEIRA, Regina. Educação Musical no Brasil. Salvador: Editora P\&A, 2007.

DE CERTEAU, Michel. A invenção do cotidiano: artes de fazer. Petrópolis, RJ: Vozes, 2012.

DUARTE, Raimunda Dias. Livros escolares de leitura da Amazônia: produção, edição, autoria e discursos sobre educação de meninos, civilidade e moral cristã. Campinas, SP: Pontes Editores, 2018.

FAGERLANDE, Marcelo. O baixo contínuo no Brasil: 1751-1851 - os tratados em português. Rio de Janeiro: 7letras; Faperj, 2011.

FERREIRA, Elder Magno Catanhede. História, música e sociedade: a música erudita maranhense no processo de disciplinamento social em São Luís no século XIX. 2010. 75 f. Monografia (Graduação em História) - Universidade Federal do Maranhão, São Luís, 2010.

GOUVEIA NETO, João Costa. A importância do jornal A Luta na construção da imagem musical de Antônio Rayol como o tenor maranhense na segunda metade do século XIX em São Luís. In: SIMPÓSIO NACIONAL DE HISTÓRIA CULTURAL, 6., 2012, Teresina. Anais eletrônicos... Teresina: UFPI, 2012. Disponível em: http:/gthistoriacultural.com.br/VIsimposio/anais/ Joao\%20Costa\%20Gouveia\%20Neto.pdf. Acesso em: 12 abr. 2015.

GRUPO NUCLEAR UNIVERSITÁRIO. A festa dos sons. São Luís: SIOGE, 1972.

HALLEWELL, Laurence. O livro no Brasil: sua história. São Paulo: Editora da Universidade de São Paulo, 2012.

JANSEN, José. Teatro no Maranhão. Rio de Janeiro: Gráfica Olímpica, 1974.

JORNAL PACOTILHA. São Luís, 22 nov. 1904. . São Luís, 20 dez. 1902.

JORNAL DIÁRIO DO MARANHÃO. São Luís, 25 abr. 1900. . São Luís, 10 maio 1901. . São Luís, 25 nov. 1902. . São Luís, 25 mar. 1903.

JORNAL O FEDERALISTA. São Luís, 05 fev. 1903.

LANDI, Márcio Spartaco. Lições de contraponto segundo a arte explicada de André S. Gomes. Fortaleza: Expressão Gráfica e Editora Ltda, 2006.

LEÃO, Ricardo. Os atenienses e a invenção do cânone nacional. São Luís: Instituto Geia, 2013.

MAGALHÃES, Justino. O mural do tempo: manuais escolares em Portugal. Lisboa, Portugal: Edições Colibri, 2011.

MARANHÃO. Arquivo da Arquidiocese. Livro de registro de óbito da freguesia de Nossa Senhora da Conceição da capital - 1894-1910. Livro n. 45. fl. 131. 
. Mensagem apresentada ao Congresso do Estado, 13 fev. 1901 pelo Exmo. Sr. Governador Dr. João Gualberto Torreão da Costa. São Luís, 1901.

MEDEIROS, Luís. Programa da aula de música da Escola Normal. In: MARANHÃO. Programas do Lyceu Maranhense e da Escola Normal. São Luís: Typographia a vapor do Frias \& Filho, 1890.

MEIRELES, Mário Martins. Símbolos nacionais do Brasil e estaduais do Maranhão. Rio de Janeiro: CEA, 1972.

MIGUEZ, Leopoldo. Elementos de teoria musical. Rio de Janeiro: Casa Bevilacqua, [19--].

MORGADO, José Carlos. Manuais escolares: contributo para uma análise. Porto, Portugal: Porto Editora, 2004.

MORILA, Ailton Pereira. No compasso do progresso: a música na escola nas primeiras décadas republicanas. Revista Brasileira de História da Educação, n. 12, p. 75-119, jul./dez. 2006. Disponível em: http://rbhe.sbhe.org.br/index.php/rbhe/article/view/151/160. Acesso em: 28 dez. 2015.

PERDIGÃO, Domingos de Castro. O Colégio Perdigão. In: CONGRESSO PEDAGÓGICO. São Luís: Imprensa Oficial, [Trabalhos apresentados...], 1922a.

O que se deve ler: Vade-Mecum Bibliographico. São Luiz: Imprensa Official, $1922 b$.

PERDIGÃO, Domingos Thomaz Vellez. Principios elementares de musica: em 10 lições. São Luís: Typographia do Frias, 1869a.

. Album de musica. São Luís: Manuscrito, 1869b.

PEREIRA, Elpídio de Britto. A música, o consulado e eu. Rio de Janeiro: [s. n.], 1957.

PORTO-ALEGRE, Ignacio. Solfejos do Instituto Nacional de Música. 4. v. Rio de Janeiro: Bevilacqua, [189-].

RAYOL, Antonio dos Reis. Noções de musica: extrahidas dos melhores auctores. São Luís: Typographia do Frias, 1902.

ROCHA, Heloísa Helena Pimenta; SOMOZA, Miguel. Apresentação do dossiê Manuais escolares: múltiplas facetas de um objeto cultural. Pro-posições, Campinas, SP, v. 23, n. 3 (69), p. 21-31, set./dez. 2012. https://doi.org/10.1590/s0103-73072012000300002

SALOMÃO, Kathia. O ensino de Música no Maranhão (1860-1912): lugares, práticas e livros escolares. São Luís: EDUFMA, 2016.

SOARES, Waléria de Jesus Barbosa. Produção e circulação dos livros de matemática no século XIX: autores e leitores. In: CASTRO, César Augusto; CASTELLANOS, Samuel Luis Velázquez (Org.). História da escola: métodos, disciplinas, currículos e espaços de leitura. São Luís: EDUFMA; Café \& Lápis, 2018. 